\title{
DESIGN AND IMPLEMENTATION OF A WIRELESS NETWORK SYSTEM IN A SMART CAMPUS
}

\author{
Toni Anwar'; Wendy Goh Pek Mui ${ }^{2}$ \\ ${ }^{1}$ The Sirindhorn International Thai-German Graduate School for Engineering (TGGS), Bangkok, Thailand, \\ toni_anwar@yahoo.com, tonia@kmutnb.ac.th \\ ${ }^{2}$ Altera Corporation, Penang, Malaysia,pmgoh@altera.com
}

\begin{abstract}
Article talks about the design and implementation of wireless network in Engineering Campus of University Sains Malaysia. The goals of this research is designing a network which able to bring mobility to all network users in this campus. In this research, there is a mathematical model which can be used to predict the coverage of the access point. Coverage testing had been carried out at library. Based on the original placement of the access point which done by the PPKT, the Universiti Sains Malaysia's (USM) computer center. Since the result is not so satisfying, a new design based on the characteristic of the access point and the building structure was done.
\end{abstract}

Keywords: wireless network, smart campus, library

\begin{abstract}
ABSTRAK
Artikel membahas desain dan impelentasi jaringan nirkabel di Engineering Campus of University Sains Malaysia. Tujuan penelitian adalah mendesain jaringan yang dapat menjangkau seluruh pengguna di kampus tersebut. Dalam penelitian ini, terdapat model matematika yang dapat digunakan untuk memprediksi cakupan poin akses. Pengetesan cakupan dilakukan di perpustakaan. Berdasarkan penempatan asli poin akses yang dilakukan oleh PPKT, pusat computer Universiti Sains Malaysia's (USM). Karena hasil kurang memuaskan maka desain terbaru berdasarkan karakteristik poin akses dan pembangunan struktur baru dilakukan.
\end{abstract}

Kata kunci: jaringan nirkabel, smart campus, perpustakaan

\section{INTRODUCTION}

In USA, there are quite a number of campuses, which implemented wireless network to replace existing fixed local area network. However, in Malaysia, design and implementing wireless local area network and using RFID in University is a new issue. For designing an effective WLAN, we looked through a few cases as references.

After reviewing case studies (Riezenman, 1996) etc., we noticed that most campuses implement wireless network system with the help of the expert from the wireless network system's manufacturer. Those campuses used the wireless network product provided by the Cisco. They also used many different types of Cisco Network Solution to assist them in managing the wireless network system. Those campuses gained great advantages through the implementation of the wireless network system. Below are the advantages and security issues summarized from the cases study above.

\section{DISCUSSION}

\section{Advantages of Wireless Network}

The advantages of wireless network is, first, improve the quality of delivery of education as students and teachers are able to access teaching material instantaneously. Second, enhance the interaction between parents, students, and teachers through IP communication tools. Third, increase productivity of staffs by using IP communication tools. Fourth, cultivate students' interest in learning process. Fifth, increase students' productivity as they can access to portal web and proceed with assignments without the constraint of place and time. 
Sixth, students are able to take exams with laptop and save their answer through the school's network. Seventh, enhance safety in the campus by having video based surveillance. Eight, overlaid wireless network on existing Ethernet can be used in order to solve problem of installing additional ports endlessly. This action will further save cost in long terms.

\section{Security and Network Management Issues}

Security and network management issues are as follows: by using Cisco Clean Access software, the authority is able to suspend any client who misused the network; Network Management staffs can manage the bandwidth \& network traffic with help of software; with help of CiscoWorks LAN Management Solution (LMS), the authority can manage all ports on a switch easily.

\section{Theory of Wireless Network Communication}

The growth of Wireless Local Area Network (WLANs) commenced in the mid-1980s, which was triggered by US Federal Communications Commission's (FCC) decision to authorize the public use of the Industrial, Scientific and Medical (ISM) bands. This decision eliminated the need for companies and end users to obtain FCC licenses to operate their wireless products. Since then, there has been a substantial growth in area of WLANs.

\section{Origin of Wireless Networking}

A local area network ( $\mathrm{LAN}$ ) is a communication network that interconnects a variety of data communication devices within a small geographic area and broadcasts data at high data transfer rate with very low error rates. Early attempts at networking without using coaxial cable or other wires utilized infrared (IR) transmission. An IR transceiver consist of LED (Light Emitting Diode) optimized for IR region of the spectrum as the transmitter. The receiver is made up of photodiode or phototransistor. A lens is used to concentrate or disburse the IR beam. A narrow beam width will be used as a link between two devices while wide beam width is used for link between points to multipoint. There is limitation for using IR as it cannot pass through any opaque object. Furthermore, the maximum speed attained with IR is much less, $100 \mathrm{Kbps}$, compare to wired network, which is $100 \mathrm{Mbps}$. However, IR is used to provide wireless links between devices. Many laptops, personal digital assistants (PDAs) contain IR ports. These ports are usually compatible with a standard developed by the Infrared Data Association (IrDA), a nonprofit trade that was created to define infrared standards (Stanley \& Jeffords, 2005) (Figure 1).

$\mathrm{RF}$ transmissions were also being used to link network component. The technology was successful, each vendor use proprietary techniques. Therefore, a network could only be formed by using equipments from same manufacturer. The usage of $\mathrm{RF}$ as medium is encouraging as it could cover bigger area. Furthermore, walls and physical barriers do not usually block the transmissions. As a result, the Institute of Electrical and Electronic Engineers (IEEE), through its 802 committee, has been instrumental in the development of standard for wireless networks (Cisco System, "University of California Delivers Broadband Connections to Residence Halls”, 2006).

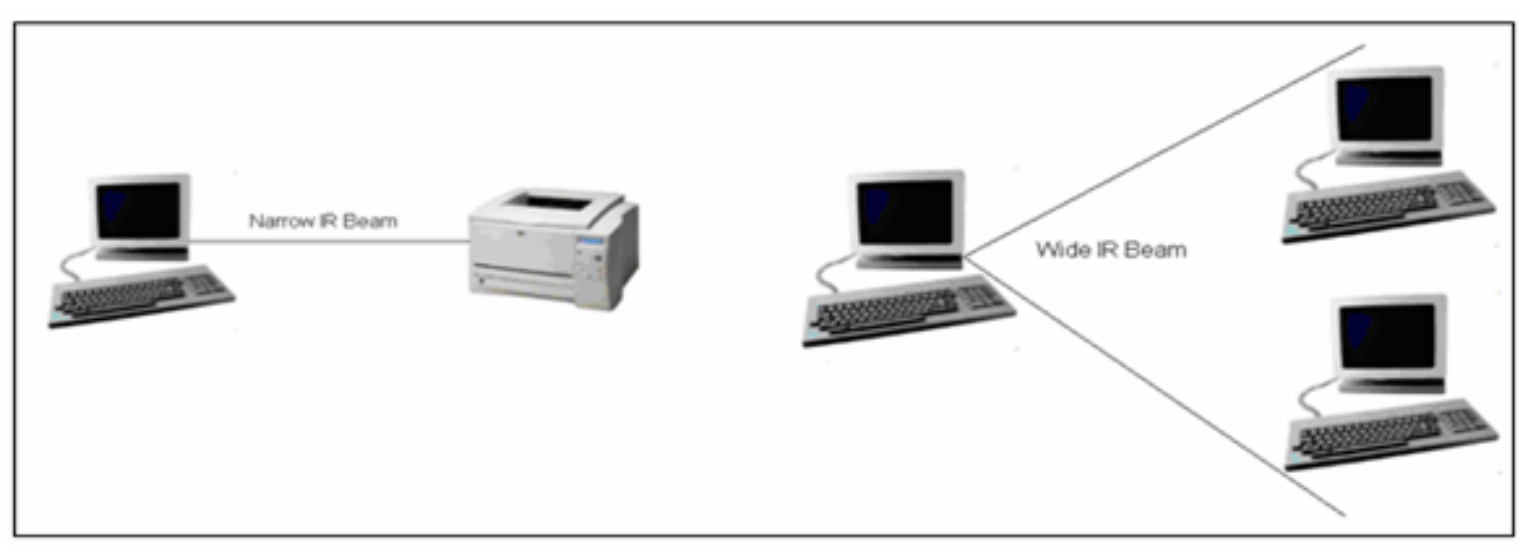

Figure 1 Narrow IR Beam and Wide IR Beam 


\section{Propagation and Coverage of IEEE 802.11 for Different Pass Loss Model]}

In Table 1 , the receiver sensitivity for different data rates at transmits power of $15 \mathrm{dBm}$ and received power level of $-15 \mathrm{dBm}$ at 1 meter are given. This reliable coverage analysis is based on path loss modeling for environment like Open Plan Building, Semi-Open Office, Closed Office with respective path loss coefficients of 2.2, 3.3 and 4.5 above the 5 meters breakpoint (up to 5 meter free space propagation with path loss coefficient equal to 2). On top of considering the path loss due to distance between transceiver and receiver, there is a margin of $10 \mathrm{~dB}$ required in relation to variation due to fading. With two antennas and Rayleigh fading channel the $10 \mathrm{~dB}$ margin reflects a reliability of $99 \%$. The reliability of coverage range might be influenced by the multipath when operating at $5.5 \mathrm{Mbps}$ and 11 Mbps in larger open spaces. Besides, the presence of obstacles like concrete wall will also affect the coverage.

\section{Wireless LAN Topology}

There are two major WLAN topologies; there are ac hoc and infrastructure. The ac hoc WLAN is a peer-to-peer network that is set up in order to serve a temporary need. There is no central coordination exists in this topology. As a result, it needs to use decentralized MAC protocol, such as CSMA/CA, with all nodes having same functionalities and thus increase the implementation's complexity $\&$ cost. In addition, it does not have the provision for access to wired network. The infrastructure WLAN makes use of a higher speed wired or wireless backbond. In this topology, mobile devices will access the wireless channel under the coordination of a Base Station (BS). As a result, infrastructure-based WLAN use centralized MAC protocols, e.g. polling (Stanley \& Jeffords, 2005) (Figure 2).

\section{Indoor Propagation Mechanism}

The propagated electromagnetic signal in indoor environment can undergo 3 (three) primary physical modes: reflection, diffraction, and scattering (Figure 3).

Table 1 Reliable Range According to Path Loss Models (Ganesh and Pahlawan, 2000)

\begin{tabular}{|c|c|c|c|c|}
\hline Data Rate & $1 \mathrm{Mbps}$ & 2 Mlops & $5.5 \mathrm{Mbps}$ & 11 Mbps \\
\hline $\begin{array}{c}\text { Receiver sersitivity for } \mathrm{BER} 10^{-5} \\
\text { Range covered } 99 \% \text { point TX power } 15 \mathrm{dBm}\end{array}$ & $-93 \mathrm{dBm}$ & $-90 \mathrm{dBm}$ & $-87 \mathrm{dBm}$ & $-84 \mathrm{dBm}$ \\
\hline Open Plan Building (range factor per $\mathrm{dB}: 1.110$ ) & $485 \mathrm{~m}$ & $354 \mathrm{~m}$ & $259 \mathrm{~m}$ & $189 \mathrm{~m}$ \\
\hline Semi Open Office (range factor per $\mathrm{dB}: 1.072$ ) & $105 \mathrm{~m}$ & $85 \mathrm{~m}$ & $69 \mathrm{~m}$ & $56 \mathrm{~m}$ \\
\hline Closed Office (range factor per $\mathrm{dB}: 1.053$ ) & $46 \mathrm{~m}$ & $40 \mathrm{~m}$ & $34 \mathrm{~m}$ & $29 \mathrm{~m}$ \\
\hline
\end{tabular}

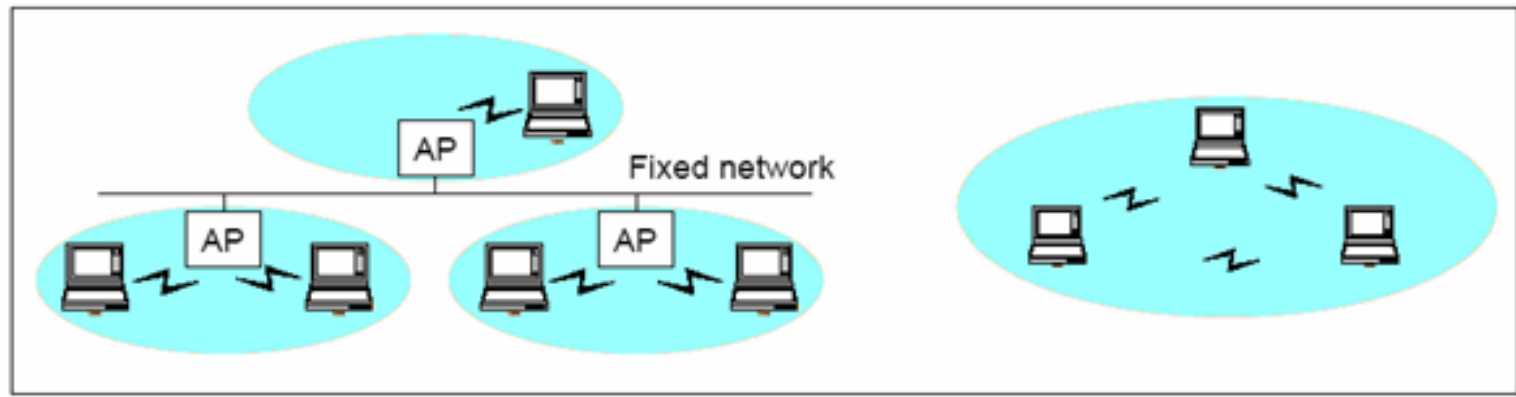

Figure 2 Infrastructure Network (Left) and Ac Hoc Network

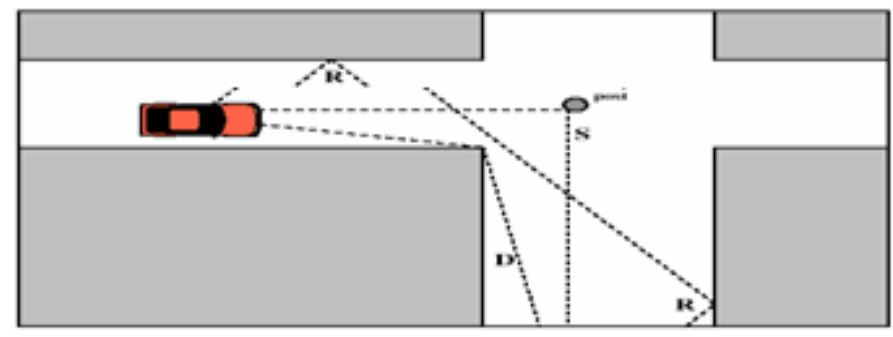

Figure 3 Sketch of Three Important Propagation Mechanism: Reflection (R), Diffraction (D), and Scattering(S) 
Reflection means when the propagated signal strikes a surface, it will be absorbed, reflected or combined, depending on the physical and signal properties. Physical properties are the surface's geometry, texture, and material composition. Signal properties are the arriving incident angle, orientation and wavelength. Materials with a high density, like concrete, tend to be harder for radio signals to penetrate, absorbing more of the energy than more porous materials like wood or drywall. Metals are excellent reflectors. The potential sources of metal around a home are numerous things like metal studs, nails, building insulation with a foil backing and even lead paint can all possibly reduce the quality of the WLAN's radio signal (Smithson, 2005) (Figure 4).
Diffraction occurs when the obstacles are impenetrable by the radio waves. The result of diffraction of a wave at an obstacle edge is that the wave front bends around and behind the obstacle edge. Indoor environments contain many types of this edges and openings, both oriented in horizontal and vertical planes (Smithson, 2005) (Figure 5).

Scattering happen if there are many objects in the signal path and the objects are small relative to the signal wavelength. The propagated wave front will break into many directions. The resultant signal will scatter in all directions adding to the constructive and destructive interference of the signal. Most modern office construction contains pressed steel Ibeams throughout the wall supports. Furthermore, construction materials such as conduit for electrical and plumbing service can add to the scattering effect (Smithson, 2005) (Figure 6).

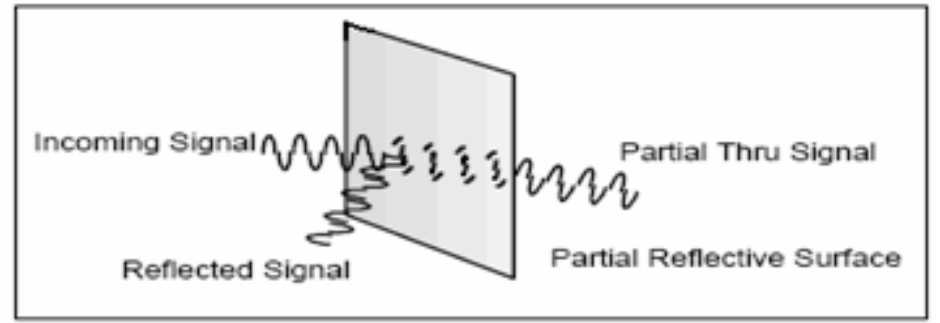

Figure 4 Reflected Signals

(Cisco System, “University of California Delivers Broadband Connections to Residence Halls”, 2006)

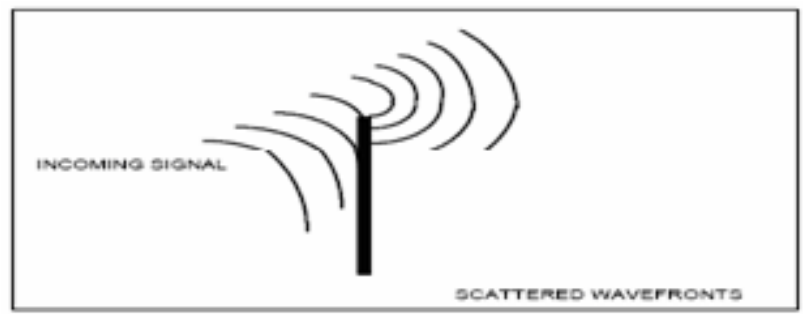

Figure 5 Diffracted Signals

(Cisco System, “University of California Delivers Broadband Connections to Residence Halls”, 2006)

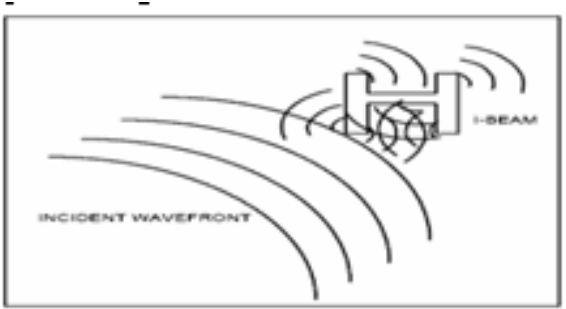

Figure 6 Scattered Wave front on an I-beam
(Cisco System, "University of California Delivers Broadband Connections to Residence Halls”, 2006) 


\section{Indoor Path Loss}

Indoor path loss is hard to be predicted or calculated. In the variety of physical barriers and materials typical of an indoor environment, these physical phenomena result in excess attenuation with respect to the free space path loss and in multipath effects.

Free space loss is the fundamental path loss for indoor environment. For an antenna to transmit ideally from the point of source, the radiating pattern should be in a spherical shape as shown in Figure 7 (Stein, 1997).

Free space path loss (FSPL) can be calculated according to Equation 1 (Cisco System, "University of California Delivers Broadband Connections to Residence Halls”, 2006).

$$
\text { FSPL }=(4 ð d / \ddot{e})^{2}
$$

$\mathrm{d}=$ Distance between the transmitter and the receiver.

ë = Wave length in meter.

$\left[\ddot{\mathrm{e}}=\mathrm{c} / \mathrm{f}, \mathrm{c}=3 \times 10^{8} \mathrm{~m} / \mathrm{s}, \mathrm{f}=\right.$ frequency desired $]$

Free space loss in decibel will be as follow

Free Space Loss $(\mathrm{FSL})=10 \log _{10}[(4 ð \mathrm{~d} /$

ë) $\left.)^{2}\right]$

From equation 2.2, when $\mathrm{f}=2.4 \mathrm{GHz}, \mathrm{d}=1$ meter,

- $\quad$ Free Space Loss (FSL)=40dB @ 1m

When $\mathrm{d}=10$ meters,
- $\quad$ Free Space Loss (FSL)=60dB @ 10m This indicates that the signal attenuates $20 \mathrm{~dB}$ per decades in free space.

For a line of site scenario, the path loss can be calculated as follow:

$$
\mathrm{PL}=\mathrm{FSL} \mathrm{ref}_{\mathrm{r}}+\mathrm{n}_{1} \cdot 10 \cdot \log _{10}\left(\mathrm{~d}_{\mathrm{tr}}\right)
$$

$\mathrm{FSL}_{\text {ref }}=$ Free Space Loss for indoor environment (normally at $1 \mathrm{~m}$ or $10 \mathrm{~m}$ )

$\mathrm{d}_{\mathrm{tr}} \quad=$ Distance between transmitter and receiver

$\mathrm{n}_{1} \quad=$ Scaling correction factor which is dependent on the attenuation of the propagation environment. It has been determined from empirical data collected (Stein, 1997), (Rappaport, 1996). Equation 3 is for large indoor free space. For line of sight application in hallway, it is fixed to be less than 2. This is due to the waveguide effect provided by properties of hallways or corridors.

\section{Wall and Floor Propagation Losses}

Obstructed path loss is much harder to be predicted as different types of materials may have different attenuation factor. A variety of different indoor configurations can be categorized for buildings with enclosed offices, or office spaces consisting of a mix of cubicles and enclosed rooms. Examples of attenuation through obstacles for various materials are shown in the table 2 .

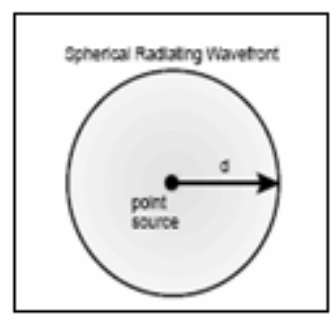

Figure 7 Free Space Radiating Pattern from a Point Source

Table $22.4 \mathrm{GHz}$ Signal Attenuation

(Cisco System, "University of California Delivers Broadband Connections to Residence Halls”, 2006)

\begin{tabular}{lr}
\hline \multicolumn{1}{c}{ Types of Material } & $\begin{array}{c}\text { Signal } \\
\text { Attenuated }\end{array}$ \\
\hline Window Brick Wall & $2 \mathrm{~dB}$ \\
Metal Frame Glass Wall into Building & $6 \mathrm{~dB}$ \\
Office Wall & $6 \mathrm{~dB}$ \\
Metal Door in Office Wall & $6 \mathrm{~dB}$ \\
Cinder Block Wall & $4 \mathrm{~dB}$ \\
Metal Door In Brick Wall & $12.4 \mathrm{~dB}$ \\
Brick Wall Next to Metal Wall & $3 \mathrm{~dB}$ \\
\hline
\end{tabular}


The propagation losses due to floors and walls and multipath effect can be calculated as equation below (Cisco System, "New High School Replaces Textbooks with Laptops”, 2006).

$$
\mathrm{L}(\mathrm{dB})=\mathrm{L}_{0}+10 \mathrm{n} \log _{10}(\mathrm{~d})+\text { ÓK }_{\mathrm{i}} \mathrm{F}_{\mathrm{i}}+\text { ÓI }_{\mathrm{j}} \mathrm{W}_{\mathrm{j}}+\mathrm{Lms}
$$

Where:

$\mathrm{L}_{0} \quad=$ power losses $(\mathrm{dB})$ at a distance of $1 \mathrm{~m}$

(40.2 dB at $2.44 \mathrm{GHz}$ frequency)

$\mathrm{n}=$ attenuation variation index with the

distance $(\mathrm{n}=2)$

$\mathrm{d}=$ distance between transmitter and receiver

$\mathrm{K}_{\mathrm{i}} \quad=$ number of floors of kind $\mathrm{i}$ in the propagation path

$\mathrm{F}_{\mathrm{i}} \quad=$ attenuation of one floor of kind $\mathrm{i}$.

$\mathrm{I}_{\mathrm{j}} \quad=$ number of walls of kind $\mathrm{j}$ in the propagat ath

$\mathrm{W}_{\mathrm{j}} \quad$ = attenuation factor of one wall of kind $\mathrm{j}$

Lms = Propagation losses due to multipath propagation and light of sight interferences effect.

Characterization of propagation losses through building materials is shown in Table 2. In order to assure a suitable reception for all wireless cards, the power range is limit at $-80 \mathrm{dBm}$ for $802.11 \mathrm{~b}$, and $-68 \mathrm{dBm}$ for $802.11 \mathrm{~g}$, so measures further from that point are not taken into account (Cisco System, "New High School Replaces Textbooks with Laptops”, 2006). However, these values may vary according to the access point chosen. We need to refer to the datasheet of the hardware chosen for further references.

\section{Radio Solution}

Spread spectrum technology was applied for WLANs in order to take care of some interference problems. Spread spectrum is a means of transmission in which the data sequence occupies a bandwidth in excess of the minimum bandwidth necessary to send it (Ganesh and Pahlawan, 2000). In Direct-Sequence Spread Spectrum (DSSS), RF energy is spread across a wide frequency band by replacing each data bit by multiple sub-bits, called chips, which occupy the same time interval. The length of chips sequence is known as the processing gain or spreading ratio.

For a 10-bit chip sequence, each 1 in the original data stream is replaced by the chip sequence, and each 0 is replaced by the inverse of the sequence. This will boost the transmission rate by factor of 10 . The more the signal is spread, the greater the processing gain, and the lower the interference threat to or from other radios using the same band. Another approach of spreading data is by Frequency-Hop Spread Spectrum (FHSS). In FHSS, it spreads radio energy over a wide band by moving between frequencies in the time. A transmitter jumps from one narrowband frequency to another at a specific rate and in accordance with a code sequence, sending several data bits at each frequency. Interference may be minimized by limiting the time spent at each frequency as the chance of two transmitters using the same frequency at same time will be lowered. For example, if the spectrum is divided into $1 \mathrm{MHz}$ channels, the time spend on a channel must not be more than $400 \mathrm{~ms}$ out of any 20 seconds on a channel in $900 \mathrm{MHz}$ band, and no more than $400 \mathrm{~ms}$ out of 30 seconds at $2.4 \mathrm{GHz}$ band (Smithson, 2005). Spread spectrum also helps to prevent two separate networks installed in the same building from getting in each other's way.

In many cases, all access points in one building's are programmed with the same frequency hopping or spreading code. When a single code cannot handle all users, one solution is to break the network up to several smaller sub-network, each one with its own code. With DSSS, the codes for such system would be designed to be mutually orthogonal, so that transmissions from one network will look like a random noise to another network. Therefore, internetwork interference will be minimized.

Many WLANs adopt media access scheme known as CSMA/CA. In this system, when a computer senses that the channel is idle, the station does not send data immediately. It waits for a period of time called interframe space (IFS). Even though the channel may appear idle when it is sensed, a distant station may have already started transmitting. The distant station's signal has not yet reached this station. The IFS time allows the front of transmitted signal by the distant station to reach this station. If after the IFS time, the channel is still idle, the station can send according to the contention time (Smithson, 2005). As a result, a number of collisions will be greatly reduced. CSMA/CA has no effect on multipath interference as they employ wideband receivers, both DSSS and FHSS, helping to mitigate this multipath interference problem. Figure 8 is the flowchart which shows the process of CSMA/CA. 


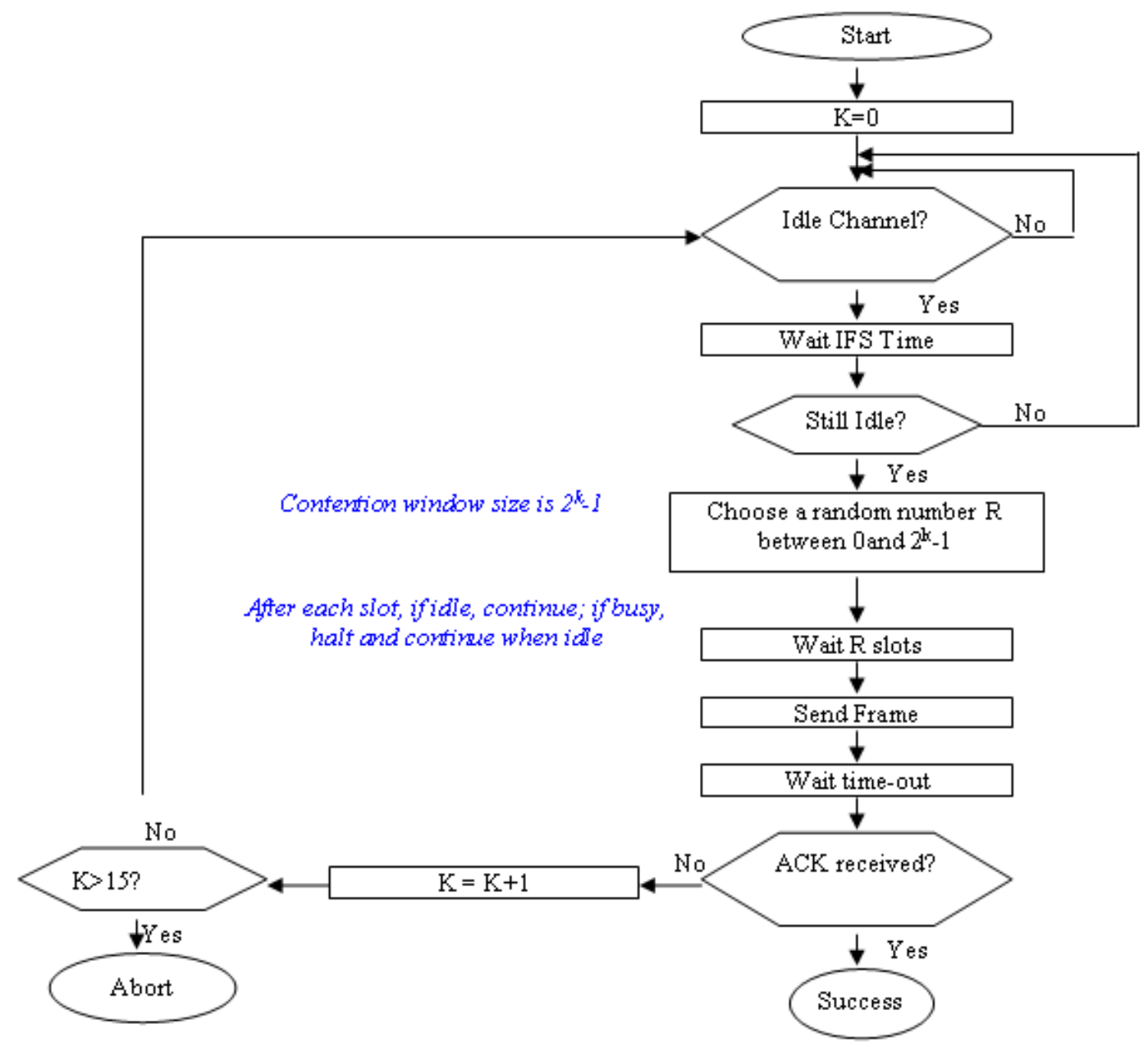

Figure 8 Flow Diagrams for CSMA/CA

\section{Calculation of Indoor Propagation Loss}

By considering the office wall, the signal attenuation of $6 \mathrm{~dB}$ as shown is Table 2, we perform the calculation of propagation losses for a few distances and walls. From Equation 2, we calculated the free space loss at 1 meter is $40 \mathrm{~dB}$. For Lms, the value is taken from part 2.2.2.1. The calculation is performed by using Equation 4.

For transforming $\mathrm{dB}$ to $\mathrm{dBm}, 30 \mathrm{~dB}$ needs to be added.

$$
\begin{aligned}
\mathrm{dBm} & =10 \log _{10}(\mathrm{~A} / 0.001) \\
& =10 \log _{10}(\mathrm{~A})+10 \log _{10}(1000) \\
& =10 \log _{10}(\mathrm{~A})+30
\end{aligned}
$$

$\mathrm{d}=5$ meters, number of wall $=1$

\begin{tabular}{|c|c|}
\hline $802.11 \mathrm{a}$ & 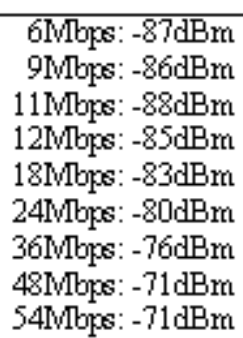 \\
\hline $802.11 \mathrm{~b}$ & $\begin{array}{l}\text { 1Mbps: }-92 \mathrm{dBm} \\
\text { 2Mbos: }-89 \mathrm{dBm} \\
\text { 5.5Mops: }-88 \mathrm{dBm} \\
\text { 11Mops: }-83 \mathrm{dBm}\end{array}$ \\
\hline $802.11 \mathrm{~g}$ & $\begin{array}{r}\text { 1Mbps: }-95 \mathrm{dBm} \\
\text { 2Mbss: }-91 \mathrm{dBm} \\
5.5 \mathrm{Mbps}:-89 \mathrm{dBm} \\
6 \mathrm{Mbps}:-87 \mathrm{dBm} \\
9 \mathrm{Mbps}:-85 \mathrm{dBm} \\
11 \mathrm{Mbps}:-88 \mathrm{dBm} \\
12 \mathrm{Mbps}:-80 \mathrm{dBm} \\
18 \mathrm{Mbps}:-80 \mathrm{dBm} \\
24 \mathrm{Mbps}:-77 \mathrm{dBm} \\
\text { 36Mops: }-73 \mathrm{dBm} \\
48 \mathrm{Mbps}:-72 \mathrm{dBm} \\
54 \mathrm{Mbps}-72 \mathrm{dBm}\end{array}$ \\
\hline
\end{tabular}

$$
\begin{aligned}
\mathrm{L}(\mathrm{dB}) & =40 \mathrm{~dB}+10(2) \log _{10}(5)+6+10 \\
& =70 \mathrm{~dB} \\
& =100 \mathrm{dBm}
\end{aligned}
$$

Table 3 Receiver Sensitivity for Different Transmit Rate 
$\mathrm{d}=10$ meters, number of wall $=2$

$$
\begin{aligned}
\mathrm{L}(\mathrm{dB}) & =40 \mathrm{~dB}+10(2) \log _{10}(10)+2(6)+10 \\
& =82 \mathrm{~dB} \\
& =112 \mathrm{dBm}
\end{aligned}
$$

The transmission power of the AP we used is in this research is $18 \mathrm{dBm}$. Therefore, after deducting the propagation loss of the wall; the received signal will be $-82 \mathrm{dBm}$ and $-94 \mathrm{dBm}$. For the library used, we choose DWL-7200AP - TriMode Dual-band 802.11a/b/g (2.4/5GHz) Wireless $108 \mathrm{Mbps}$ Access Point with PoE. From the datasheet, the following table shows the receiver sensitivity of the chosen AP.

From Table 3, we noticed that for lower transmit rate, their signal can be detected by the receiver. Therefore, walls will be an obstacle which weakens the receiving signal. If the only one wall is obstructing the signal path, the signal still can be detected. If there are two walls in the path, the signal will be greatly weaken and cause lost of signal.

\section{Design of Wireless Network}

In the design of a digital campus, both infrastructure and ac hoc topologies will be used. Types of topologies chosen for the design will depend on the structure of the buildings. This will be discussed in each design. There are two types of WiFi, indoor and outdoor wireless AP (Access Point), which will be used. The outdoor AP, as well as the indoor AP will be connected as infrastructure WLAN. The purpose of installing an outdoor AP is to ensure the access to World Wide Web in any area in the campus. The wireless system will base on the IEEE 802.11 standard. This will ensure interoperability between the products from different manufacturers (Figure 9).

\section{Library}

For the library design, 4 (four) APs will be needed as there are four floors. Each floor will contain one WiFi which connects to the main switch by a CAT- 5 cable. At each floor, the AP will be installed at the center of the open area. This is to ensure a maximum coverage is obtained. It is predicted that one AP is sufficient to cover the study area of the library as the length of library building is only 80 meters and the width is 32 meters. This will ensure library user to manage accessing the Ethernet at any corner of library.

However, for the office area at ground floor, Router/Wireless Modem (WM) will be used as the environment of office is different from the open area of library. Doors and walls may weaken the signal and cause difficulties for staffs to access to Ethernet for their daily routine work. Although wireless modem may have limited access, it is sufficient for office used. Therefore, using wireless modem will be a wise choice.

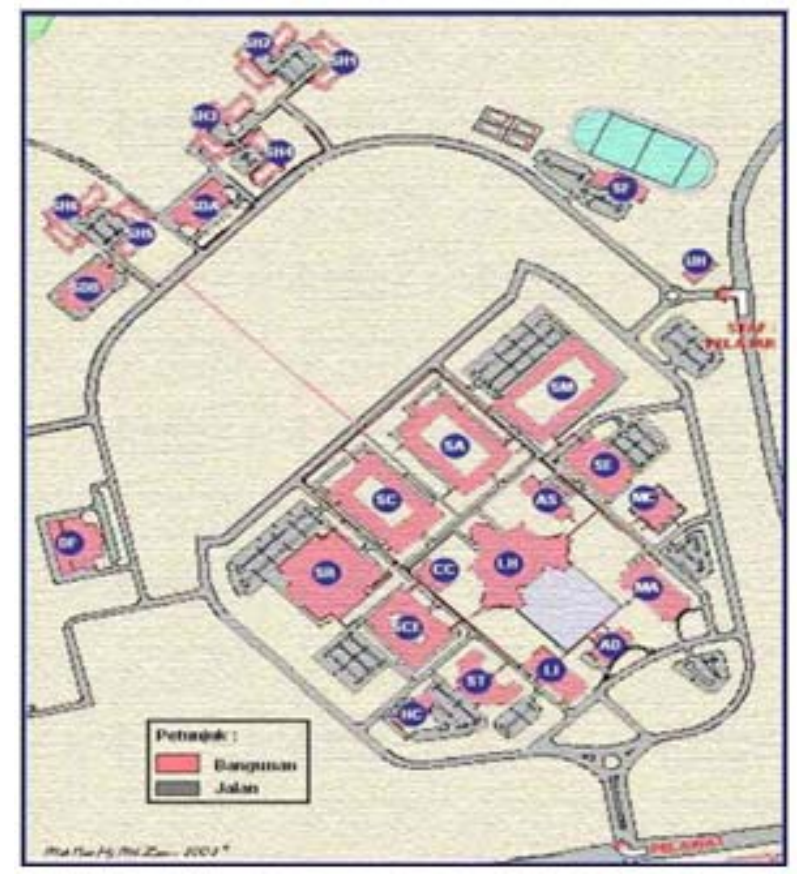

Figure 9 Map of USM Engineering Campus 
At the first and second floor, the AP will be placed about 4 (four) meters away from the existing switch as shown as star shape in the layout. This is to ensure the AP is able to cover the area on the left of the library. CAT-5 cable was used to connect the AP to the switch. At first and second floor, the reading area at the end of right hand corner may receive weak signals due to the obstruction of the book's shelves. Meanwhile, the media room at second floor is quite far from the AP. Therefore, an external antenna can be used to extend the signal from AP to that room. However, there is another choice which can be applied. A Router (WM) can be connected to the port by using RJ-45 cable. This will form a small sub-network in the room (Figure 10).

\section{Healthcare Center}

The building of Healthcare Center in USM Engineering Campus is not very big which is $52 \times 22$ $\mathrm{m}^{2}$. Therefore, one AP will be enough to cover the whole area of the buildings. The AP is placed at the center of the building. There is a hall way at both side of the location of AP. This will be the best location for installing the AP as the signals are able to propagate into the room on both sides of the hall way. Signal may be attenuated, but it is still able to cover most areas which need wireless network's facilities.

\section{School of Electrical and Electronic}

In School of Electrical and Electronic, there will be 3 (three) APs used in each floor except $4^{\text {th }}$ floor. Two APs will be needed at $4^{\text {th }}$ floor as it only consists of front part of the building. The locations of APs in each floor are like a triangle shape. Each AP will be able to cover a range up to 35 meters which is under the specification limit of an AP. The coverage area of each AP will overlap in certain areas. Users may choose which AP to use as their wishes. Wood, plaster, and glass will be serious barriers for radio transmission. Therefore, although it is predicted that lecturers will be able to access to the AP even in room, the signal may be attenuated or weak signal may be received. For best performance, the door of the lecturer's room may be modified. Which means glass window will need to be placed at the upper part of the door. There will be a Router/Wireless Modem (WM) being fixed at the office. This is due to the office environment which has common obstacles such as desk, filling cabinet, and reinforced concrete. Besides, all administrative confidential information will be more secured as WM only allows authentic persons to access to it.

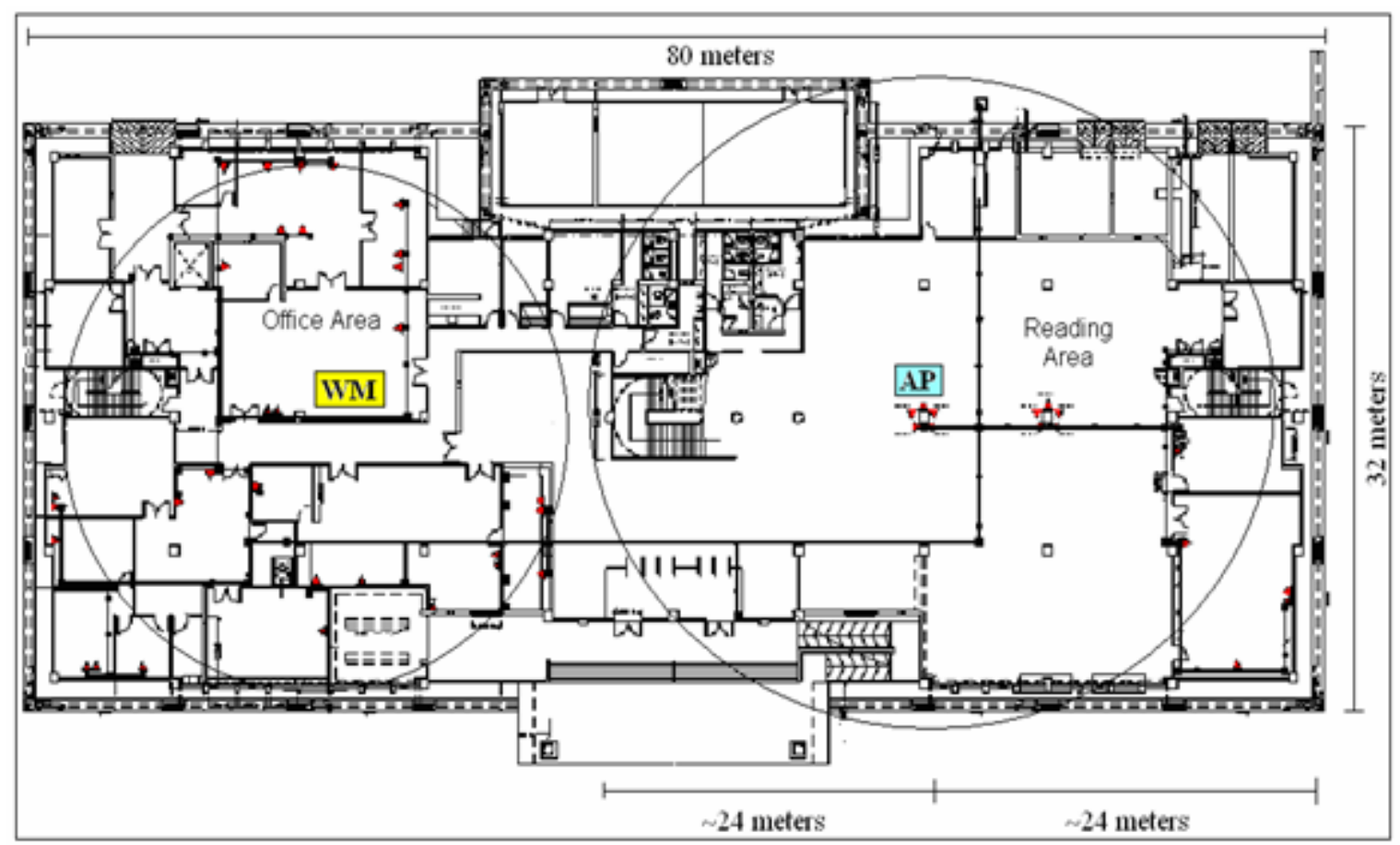

Figure 10 Floorplan of Library’s Ground Floor 


\section{Cafeteria}

In each cafeteria, the AP will be placed at the center of the open area. This is the best solution for a maximum coverage over the whole area. There will not be much problem of coverage in café as it is an open space without many obstacles. For the staff café, it is predicted that signal can also be received in post office beside the staff café building, as the door of the post office is always open. In the hall area, weak signal may be detected as there will be attenuation after the signal pass through the wooden door. For Jaya café and ground floor of Lembaran café, one AP is sufficient. At the first floor of Lembaran café, there are administrative offices of each hostel. Since each office is using a glass door, the signal will be able to propagate into the office. However, in office environment, signal received may be weaken. For a best solution, they may use external antenna outside the office for best reception of the signal.

\section{Administrative Building}

The Administrative building consists of 2 (two) floors. At ground floor, there are two offices which are the security and UPI (Unit Perhubungan Industry/Industrial Relationship Unit) offices. Since the security office is dealing with something confidential, it will be more appropriate to place a router there. With the function of router, only authenticated persons are allowed to access to the router in security office. Besides, it is not so suitable to use an AP in office environment as there are desks, filling cabinet and some other obstacles inside.
This concept is applied to other offices in administrative department. Those who are in seminar room and need to have wireless access can get the permission from the UPI office. This may seems to be troublesome, but, it is a way to secure all confidential information being hacked.

\section{Hostel}

There are two types of hostel buildings. Hostel SH2, SH3 and SH6 are considered as type A which consists of 3 wings. Hostel SH1, SH4, and SH5 are type B building which has 2 wings only. These hostels contain four floors each. There will be three AP needed for type A's building and two AP for type B building. Each AP will be placed at $1^{\text {st }}$ floor of each building. Signals may propagate around the AP with a radius of 50-100 meters depending on the structure of building and the AP chosen. For this case, the signal may not propagate too far as the signal need to pass through the glass window to be received by the client in the room.

\section{Lecture Hall}

The lecture hall complex is big. Therefore, three APs will be needed to cover all lecturer halls. The installation of AP is according to the buildings structure. Lecture hall 1, 2, and 3 will share one AP. The AP will be placed at the center of the foyer of these lecture halls as shown in Figure 3.16. Lecture hall 4, 5, 6 and 11 will share one AP., while lecture hall 7, 8, 9, and 10 will share another AP. As for lecture hall 1,2 , and 3 , the AP for the rest of the lecture hall will be placed at the center of the foyer (Figure 11).

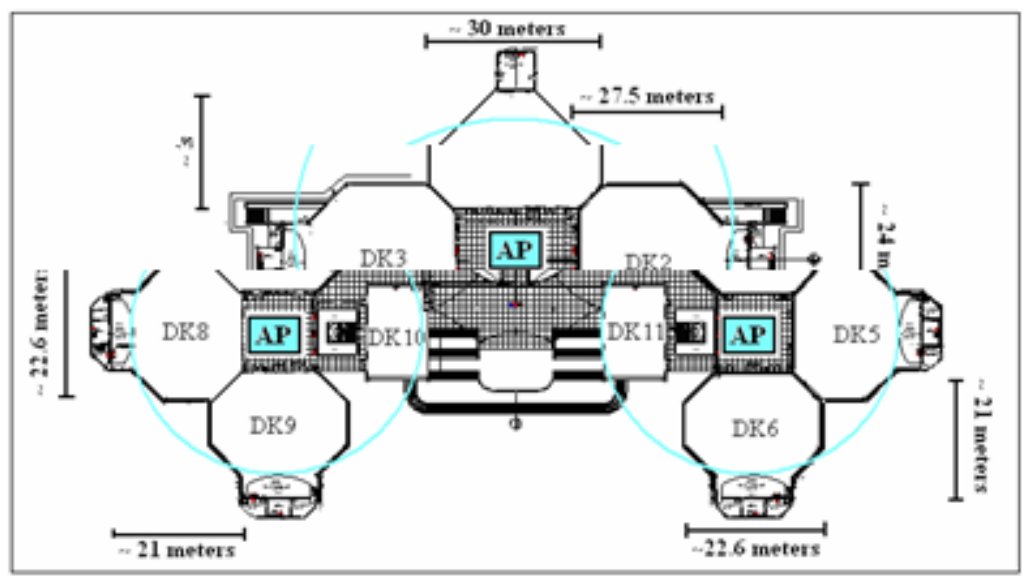

Figure 11 Floorplan of Lecture Hall Complex 


\section{Guard House}

In guard house, we choose to use an AP to form a wireless network. However, the AP will be a closed AP which is not open for public uses. This AP will be able to communicate with the RFID reader which can be installed at the entrance of the campus. Data read by the RFID reader will be stored in a computer. The ability of the reader to communicate with the AP will allow the authority to access the reader data directly from the network. Otherwise, they need to get the data from the guard house. That will be rather troublesome.

\section{Results of Coverage Testing in Library}

The location of APs during the testing is not according to the design. This was the old location of APs. For ground floor, the placement of AP_1 is same as design. The speed is excellent and signal strength is very good at location 1 . Apart of that, signal from AP_2 which is located at first floor can be detected at location 1 as well. The speed is quite good while the signal strength is poor.

At first floor, the AP_2 is placed at the right corner which is not so good in providing coverage to the whole area of it. At location 1, the speed and signal strength is excellent as it is very near to the AP_2. The speed and signal received at location 2 are good also as there are no obstruction between the AP_2 and the client. In location 3, there are some obstructions like book shelves, tables etc. Therefore, the signal received is considered poor. However, the data transmission speed is considered quite well. This may be due to the fact, that less people are using the AP. At location 4, the signal strength is very poor. This may be due to free space propagation loss and multipath propagation loss. The data link speed is rather good at location 4 . There are signal received from AP_1 at each locations. But, all signals received are very poor which is $20 \%$ only (Table 4 ).

There is no AP being installed at second floor. As a result, there is only area near to the air well manage to received signal from AP_1 and AP_2. The signal strength received is poor while the speed is still under acceptable limit. Location 2, 3 and 4 cannot receive any signal from the AP.

After the testing, it is found out that the location of each AP must be redesigned to ensure maximum coverage. More APs need to be added in order to provide wireless access at every floor of library.

\section{Benefit of Implementation of Wireless Network}

This wireless network is very useful for improving the administrative work flow. The existence of a wireless network system enables all types of information to be stored in the database. The authenticated users will be able to access the database anytime, anywhere in the campus as long as there is a mobile device with them. Furthermore, storing information in database will enable the data to be recalled on the spot without the need of asking an office boy to deliver the files from one place to another. This solution not only saves the work processing time, but, also saves the human resources. By assigning higher transfer speed for administrative purposes, the efficiency of administrative work will be greatly increased.

Implementation of WLAN in faculties enables the e-learning process. Lecturers can upload their teaching material to their website and students will be able to download them before attending the

Table 4 the Speed and Signal Strength Tested in Library

\begin{tabular}{|c|c|c|c|c|c|c|c|c|c|}
\hline \multirow{2}{*}{$\begin{array}{c}\text { Access Point } \\
\text { (Speed Mlpps, Signal Strength \%) }\end{array}$} & \multirow{2}{*}{$\begin{array}{c}\text { Ground } \\
\text { Floor }\end{array}$} & \multicolumn{4}{|c|}{ First Floor } & \multicolumn{4}{|c|}{ Second Floor } \\
\hline & & 1 & 2 & 3 & 4 & 1 & 2 & 3 & 4 \\
\hline AP_1 & $\begin{array}{l}54 \\
80\end{array}$ & $\begin{array}{l}11 \\
20\end{array}$ & $\begin{array}{c}5.5 \\
20\end{array}$ & $\begin{array}{l}11, \\
20\end{array}$ & $\begin{array}{l}11, \\
20\end{array}$ & $\begin{array}{l}11 \\
40\end{array}$ & $\mathrm{NC}$ & $\mathrm{NC}$ & $\mathrm{NC}$ \\
\hline $\mathrm{AP}_{2} 2$ & $\begin{array}{l}36 \\
40\end{array}$ & $\begin{array}{l}54 \\
100\end{array}$ & $\begin{array}{l}54 \\
80\end{array}$ & $\begin{array}{l}34 \\
40\end{array}$ & $\begin{array}{l}18, \\
20\end{array}$ & $\begin{array}{l}11, \\
40\end{array}$ & $\mathrm{NC}$ & $\mathrm{NC}$ & $\mathrm{NC}$ \\
\hline
\end{tabular}

$\mathrm{NC}=$ No Connection 
class. Besides, lecturers can change their teaching material from text books to laptops. The screen of the laptop will be projected for the class to view. Everything can be done within the laptop. Besides, lecturers will be able to connect to internet to get latest information and share with students even during the class period. This type of teaching method is already proven, which will make students more engaged in learning. As for the future, students are expected to have their own laptops. At that time, all types of text books will be changed to laptop. Every student will access to teaching material via their laptop. This will make them able to do their education anytime, anywhere in the campus area. Students will need to do all assignments, tutorial, laboratory report by using their laptops. No paper works need to be passed up as they can pass up their work via email to the lecturers. This will help to save a lot of nature resources such as paper.

Wireless network system will enable the usage of IP phone. Staffs, lecturers, and students will be able to contact with each other easily. This application enables the university to save cost in the local phone usage. Besides, student will be able to have discussion with their lecturer more frequently through the IP phone. This will help to improve the relationship between lecturer and students.

At the Lecture Halls, the AP not only provides wireless access to all students, it is also able to communicate with the RFID reader. It is desired to install RFID reader at the door of each lecture hall. Every student who wants to attend the lecture will need to scan their student ID card at the reader. Therefore, lecturers do not need to waste any time taking attendances during class. They just need to access the database and recall the attendance of students which were read by the RFID reader.

WLAN should be implemented at the clinic in the campus as well. With the WLAN in the clinic, doctor and nurses will be able to access to student medical information by just clicking a few buttons. This can be done by fixed LAN as well. However, the reason we need to implement WLAN is to save cost as no cable routing is required in order to connect to each device. Apart of that, students who accompany their friends to the clinic can still continue with their works or keep themselves with the current affairs while waiting for their friends. Installing WiFi based RFID in clinic is a must. All information provided by the RFID tags and reader will be stored in the server. The authority can recall the information anytime when needed. There are quite a number of advantages of using RFID in clinic. RFID is best suited in tracking applications. It can provide better inventory management such as equipments, medicines and rooms. Besides, it is able to prevent the theft of equipment and medicine. By creating a WLAN in hostel, this will save a lot in cost as installing fixed network in each and every room require more cable and the maintenance work is more complicated. In each room, students need to buy a switch to connect to each computer as there are four people sharing a room. Therefore, installing WiFi in hostel will be a wise choice. By having a wireless AP, implementation of WiFi based RFID system in hostel will be possible. However, for installing the WiFi based RFID system in hostel, main entrance should be made and gates need to be fixed for each building. Only students who stay in that building are allowed entering the hostel. This is to ensure the safety of students especially female ones.

\section{Health Concern}

Wireless LAN utilize microwave signal which is similar to those in mobile phones. Therefore any health concern will be the same as mobile phone. The transmitted power of a typical wireless AP is less than $100 \mathrm{~mW}$. While the radio wave emitted by a GSM handset will have power transmitted as high as 2 Watts. After comparing both of the value, it is found out that the wireless AP is safe to be used.

\section{CONCLUSION}

The design in this research is based on the coverage characteristic of an AP. AP from different manufacturer may have different specifications. Therefore, analyses of the specifications and the building structure have to be done before the design of the wireless network. Some APs may have higher transmission power and higher gain antenna which are able to provide stronger signals. In this research, there are mathematical equations shown in order to predict the coverage of an AP. However, this prediction may differ from the measurement we obtained from the real environments. Therefore, mathematical model is used for design references. In order to get the exact coverage of an AP, coverage testing needs to be carried out. The testing can be done by using mobile devices, e.g. laptop with wireless adapter installed, or PDA. For advanced coverage testing, a ray optics tracing tools can be used. The detail of this tool is described (Smithson, 2005). 
In the library, it is desired to have a laptop's battery recharging station. This is to make sure that those who use their own laptop in library are able to continue using their laptop although the battery dies out in the library. Lockers with power plug inside should be made for battery recharging purposes. During the recharging period, the owner can lock their laptop in the locker and be able to have a rest at the cafeteria or do some studies in the library. This type of facilities will greatly benefit library's users who need to do their work in longer period with their laptops.

Another future work which can be done is transforming a digital campus into a digital town which is able to support E-services and E-learning to the public in the surrounding areas. This step will help to stimulate the development of a city. An outdoor AP with wider coverage range, 500 meters (Anwar, 2005) can be installed inside the campus. Computer and Communication Center of USM will be the one who manage the network system for the whole town.

\section{REFERENCES}

Anwar, Toni and I Made Murwantara. "From A Digital Campus to A Digital City: Infrastructure Support for e-Services," Journal of School for Computer Science, Universitas Pelita Harapan, Vol.3 No.1, January 2005, ISSN: 1412-9523.

Cisco System. April 2006. Customer Case Study, "New High School Replaces Textbooks with Laptops”.

10 January 2006. Customer Case Study, "University of California Delivers Broadband Connections to Residence Halls". 2006. Customer Case Study, "Schools

District Improves Communications, Education and Safety". . 4 January 2006. Customer Case Study, "Cleveland State's WoWnet Gives Faculty and Students Convenient Access to Web and Courseware".

Forouzan, Behrouz A. 2007. Data Communications and Networking. $4^{\text {th }}$ Edition. McGraw Hill International.

Ganesh, Rajamani and Kaveh Pahlawan. 2000. Wireless Network Deployments. Kluwer Academic Publihers.

Haykin, Simon. 2007. Communication Systems. $4^{\text {th }}$ Edition. John Wiley \& Sons.
Lloret, Jaime, Jose J. López, Carlos Turró, and Santiago Flores. “A Fast Design Model for Indoor Radio Coverage in the $2.4 \mathrm{GHz}$ Wireless LAN", Department of Communications Universidad Politécnica de Valencia, Camino Vera s/n 46022 Valencia, SPAIN, 20-22 September 2004.

Nicopolitidis, P., M.S. Obaidat, G.I. Papadimitriou, and A.S. Pomportsis. 2003. Wireless Network. John Wiley \& Sons, LTD.

Rappaport, Theodore S. 1996. Wireless Communications Principles and Practice. Upper Saddle River, New Jersey: IEEE Press/Prentice Hall PTR.

Riezenman, Michael J. 1996. Local Area Network Go Wireless. Publish in IEEE SPECTRUM.

Smithson, Allan Geoffrey. "Wide Area Radio Channel Modeling Across the Indoor. Outdoor Interface,” A Thesis submitted for the degree of Doctor of Philosophy The University of Bath, Department of Electronic and Electrical Engineering, October 2005.

Stanley and Jeffords. 2005. Electronic Communication: Principles and Systems. Thomson, Delmar Learning.

Stein, John C. 1997. "Indoor Radio WLAN Performance Part II: Range Performance in a Dense Office Environment," Harris Semiconductor, 2401 Palm Bay, Florida 32905.

White, Curt M. 2002. Data Communication and Computer Networks: A Business User's Approach. $2^{\text {nd }}$ Edition. Course Technology. 